\title{
A detailed study of a cylinder activation concept by efficiency loss analysis and 1D simulation
}

\author{
Thomas Buitkamp ${ }^{1} \cdot$ Michael Günthner ${ }^{1} \cdot$ Florian Müller $^{1} \cdot$ Tim Beutler $^{1}$
}

Received: 10 July 2020 / Accepted: 25 August 2020 / Published online: 4 September 2020

(c) The Author(s) 2020

\begin{abstract}
Cylinder deactivation is a well-known measure for reducing fuel consumption, especially when applied to gasoline engines. Mostly, such systems are designed to deactivate half of the number of cylinders of the engine. In this study, a new concept is investigated for deactivating only one out of four cylinders of a commercial vehicle diesel engine ("3/4-cylinder concept"). For this purpose, cylinders $2-4$ of the engine are operated in "real" 3 -cylinder mode, thus with the firing order and ignition distance of a regular 3-cylinder engine, while the first cylinder is only activated near full load, running in parallel to the fourth cylinder. This concept was integrated into a test engine and evaluated on an engine test bench. As the investigations revealed significant improvements for the low-to-medium load region as well as disadvantages for high load, an extensive numerical analysis was carried out based on the experimental results. This included both 1D simulation runs and a detailed cylinder-specific efficiency loss analysis. Based on the results of this analysis, further steps for optimizing the concept were derived and studied by numerical calculations. As a result, it can be concluded that the 3/4-cylinder concept may provide significant improvements of real-world fuel economy when integrated as a drive unit into a tractor.
\end{abstract}

Keywords Cylinder deactivation · Efficiency loss analysis · 1D simulation · Engine operating point shift · Gas exchange

$\begin{array}{ll}\text { Abbreviations } \\ \text { 1D/3D } & \text { One-/three-dimensional } \\ \text { BDC } & \text { Bottom dead center (of piston) } \\ \text { (B)MEP } & \text { (Brake) mean effective pressure } \\ \text { BSFC } & \text { Brake specific fuel consumption } \\ \text { CA } & \text { Degrees crank angle } \\ \text { CAL } & \text { Cylinder activation line } \\ \text { CFD } & \text { Computational fluid dynamics } \\ \text { DOHC } & \text { Double overhead camshaft } \\ \text { ECU } & \text { Engine control unit } \\ \text { EVO } & \text { Exhaust valve opening (timing) } \\ \text { EGR } & \text { Exhaust gas recirculation } \\ \text { IVC } & \text { Intake valve closing (timing) } \\ \text { OHV } & \text { Overhead valves } \\ \text { TDC } & \text { Top dead center (of piston) } \\ \text { TPA } & \text { Three-pressure analysis }\end{array}$

Florian Müller

florian.mueller@mv.uni-kl.de

1 Lehrstuhl für Antriebe in der Fahrzeugtechnik (LAF), Fachbereich Maschinenbau und Verfahrenstechnik, Technische Universität Kaiserslautern, 67663 Kaiserslautern, Germany

\section{Introduction}

In recent years, a multitude of different concepts for realizing an engine operating point shift have been developed and implemented in series applications for both gasoline and diesel engines. In most cases, the objective is to use more efficient operating regions of the engine map and, therefore, improve fuel consumption [1]; in some cases, the focus is also on increasing the exhaust gas temperature to heat up or maintain the temperature of the exhaust aftertreatment system, especially for diesel engines [2,3]. Besides classic "downsizing" or "downspeeding" approaches on the one hand and complex operating strategies in hybrid concepts on the other, such an operating point shift can also be achieved by so-called "dynamic downsizing", i.e. the deactivation of one or more cylinders of a multi-cylinder engine depending on the operating point. Such concepts were first investigated in the 1980s by Cadillac and Mercedes-Benz [4] and also introduced into series production by Cadillac albeit with very limited success at the time. In recent years, however, cylinder deactivation has attracted renewed interest and is increasingly applied in series production engines.

In most of the current cylinder deactivation designs, both the air and the fuel supply are switched off for the inactive 
cylinders. For this purpose, usually the intake and exhaust valves of these cylinders are deactivated, which eliminates the gas exchange losses. In addition, the gas trapped inside the deactivated cylinders acts as a pneumatic spring, resulting in only minor in-cylinder process losses, mainly due to heat transfer to the combustion chamber walls. As there are no gas forces due to combustion in the deactivated cylinders and piston, lateral forces are, therefore, significantly reduced, friction loss is also comparatively low.

Usually, exactly half of the number of cylinders are disabled in the deactivated mode [5-7]. More recently, however, there have been new concept proposals aiming at deactivating only one cylinder of a multi-cylinder engine [8-10]. Although the load increase is lower in these cases, this may still result in increased consumption benefits in real operating situations. This is primarily due to the fact that cylinder deactivation can be used more frequently in practical operation, since it covers a larger portion of the entire engine operating map [11]. Honda's "variable cylinder management" (VCM) system [12] is another exception to the rule, enabling the deactivation both of three and only two out of six cylinders. These different deactivation modes are used in different regions of the operating map and also extend the available operating range for cylinder deactivation.

Yet another approach can be found in the concept of "rotating" cylinder deactivation on a multi-cylinder engine developed by Schaeffler [13]. This means that on a three-cylinder engine, either only cylinder 2 or cylinder 1 combined with cylinder 3 is switched off alternately. The result of this strategy is a uniform firing order, with each cylinder firing only every second engine cycle. This concept has also been investigated by Ford in the EcoBoost 1.01 three-cylinder engine [14], but was not transferred to series production. The Dynamic Skip Fire (DSF) system presented by Tula, on the other hand, allows individual cylinders to be deactivated when required $[15,16]$. For example, on a V8 engine, any possible combination of active and inactive cylinders can be realized. A similar concept has been successfully transferred to a concept diesel engine [17].

The operating point shift achieved by cylinder deactivation has a positive effect on efficiency, especially in the case of gasoline engines due to the reduction of throttling losses. Nevertheless, some investigations also show relevant fuel efficiency benefits achieved by cylinder deactivation also on diesel engines. For example, a study described in [18] revealed significant fuel economy gains at low engine load when switching off two cylinders of a four-cylinder diesel engine. According to [19], cylinder deactivation in diesel engines may result in fuel consumption advantages of up to $17.5 \%$ while simultaneously increasing exhaust gas temperature. In [20], an improvement of fuel consumption of $10-30 \%$ through cylinder deactivation is reported for a sixcylinder diesel engine. As already mentioned, switching off one or more cylinders can also be considered as a both effective and efficient measure for raising the temperature in diesel exhaust aftertreatment systems [3, 21].

The concept to be studied in the current publication aims at switching on or off only one cylinder of a four-cylinder engine depending on current torque demand. In this case, cylinders 2-4 are operated with even firing intervals according to the firing order of a "real" three-cylinder engine, while the first cylinder is switched on in parallel to the fourth cylinder when required (" $3+1$ "-cylinder operation). This approach will be referred to as the "3/4-cylinder concept" in the following. The concept has already been tested on gasoline engines [22] and was then transferred to diesel engines. For practical realization, a number of fundamental design adjustments are required in comparison to a conventional four-cylinder engine [23]. When used as a drive unit for a tractor, this concept proved to deliver considerable fuel savings in realistic load cycles [11]. The reasons for the fuel consumption benefits achieved in significant parts of the engine map as well as for certain fuel economy penalties measured in individual operating points will be analyzed in detail using both 1D simulation of the real engine operation and a detailed loss analysis. Based on this analysis, further steps for the optimization of the concept will be identified and evaluated by simulation.

\section{Engine specifications and experimental set-up}

A John Deere four-cylinder diesel engine was used as a basis for the modifications described above. The engine has a common rail injection system with a maximum injection pressure of 2000 bar and a two-stage turbocharging system. In this system, the high-pressure turbine is controlled by a wastegate actuated by the intake pressure (captured between the high-pressure compressor and the charge air cooler), while the low-pressure turbine has no variabilities. The base engine also uses exhaust gas recirculation (EGR) via a highpressure loop between the exhaust and the intake manifold, including an EGR cooler. An overview of the most important technical details of the engine is provided in Table 1.

From its production state, this engine has been strongly modified to realize the cylinder (de-)activation concept described in the previous section. This included a modified crankshaft to implement the new firing order (1/4-2-3) with an adjusted mass balancing of the crank train. The series engine uses balance shafts for compensating the secondorder mass forces. As the test engine has a 3-cylinder firing order, the balancing masses of these shafts were removed, but the shafts were still driven by the crankshaft to be able to compare the modified to the base engine without additional influence of reduced friction. In a further optimization step, 
Table 1 Technical data of base engine

\begin{tabular}{ll}
\hline Maximum effective power [kW] & 130 \\
Rated speed [min & -1 \\
Maximum torque [Nm] & 2100 \\
Maximum torque speed $\left[\mathrm{min}^{-1}\right]$ & 703 \\
Displacement $\left[\mathrm{dm}^{3}\right]$ & 1600 \\
Bore [mm] & 4.5 \\
Stroke [mm] & 106.5 \\
Compression ratio [-] & 127.0 \\
Firing order (cyl. no.) & 17.3 \\
Valves per cylinder & $1-3-4-2$ \\
Emission standard & 4 \\
\hline
\end{tabular}

the drive of the balancing shafts could be modified to be able to compensate the first-order mass forces of the 3-cylinder layout. However, this was not yet realized for the current design. The mass balancing of the crankshaft was chosen to realize a $50 \%$ compensation of the mass forces in both vertical and transversal direction as a compromise. With this layout, an acceptable level of vibration of the engine was achieved. Another important topic is torque fluctuation in " $3+1$ "-cylinder operation. For the test bench, this issue could be addressed by a specific layout of the coupling between the engine and the brake (Reich TOK 1000 highly flexible coupling shaft). For the application in a series vehicle, a specially designed dual-mass flywheel would be required.

As a further measure for realizing the 3/4-cylinder concept, the valve train was modified from an OHV system with central camshaft to a DOHC layout including a mechanically fully variable valve train on both the intake and the exhaust side. For this purpose, also the layout of the inlet and exhaust ports had to be modified. The new design was optimized by 3D CFD using AVL FIRE to be as close to the series situation as possible. In addition to the deactivation of the inlet and outlet valves of cylinder 4 as required for the 3/4-cylinder concept, this valve train provides further variabilities, such as fully variable valve lift and an optional second-exhaust lift for exhaust rebreathing. These features are not discussed in more detail here as they are not relevant for the following analysis. Further details on the design and layout of this concept and on the valve train variabilities can be found in $[11,23]$. The modified cylinder head is displayed in Fig. 1.

The test engine was mounted on a stationary engine test bench equipped with a Schenck eddy current brake and an asynchronous electric machine for motoring. All four cylinders of the engine were equipped with piezoelectric pressure sensors (Kistler 6056A42), which were mounted to the cylinder head using glow plug adapters. In addition, piezoresistive low-pressure sensors (Kistler 4075A10) were installed

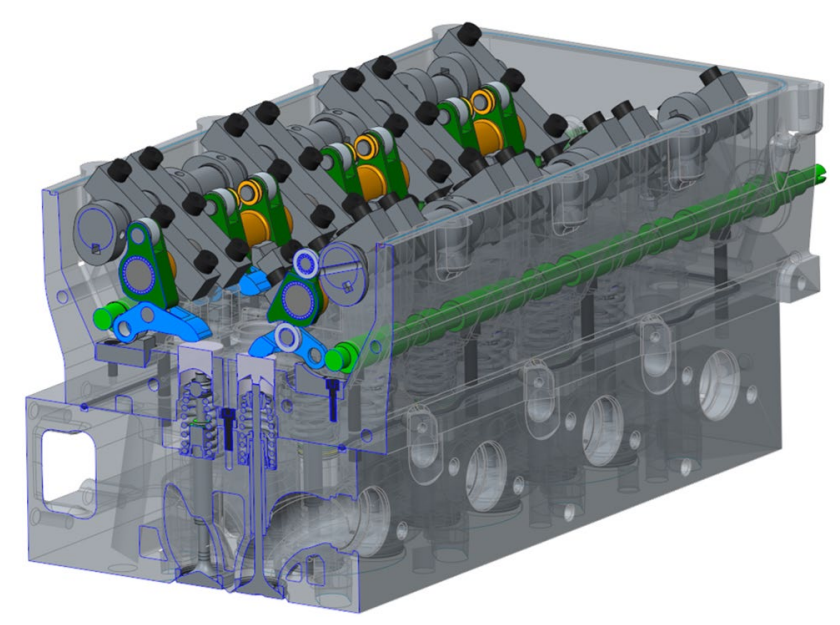

Fig. 1 Modified cylinder head with DOHC and dual fully variable valve train

both on the intake and on the exhaust side. Pressures were recorded by an AVL Indicom system using a resolution of $0.1^{\circ} \mathrm{CA}$ provided by a Heidenhain crank angle encoder. Stationary pressures were captured with Kistler PMC131 pressure transducers, while temperatures were recorded with both PT-100 and Ni-Cr-Ni sensors. A hot-film anemometer (Degussa Deguflow) was applied to measure the air mass flow rate, while fuel mass flow was determined gravimetrically by an AVL Fuel Balance. Air-fuel ratio was recorded by an ETAS lambda meter. A Fourier-transfer infrared spectrometer (AVL Sesam i60 FT) was used to determine the gaseous exhaust gas components (NMHC, $\mathrm{NO}, \mathrm{NO}_{2}, \mathrm{CO}$, $\mathrm{CO}_{2}, \mathrm{H}_{2} \mathrm{O}, \mathrm{CH}_{4}, \mathrm{~N}_{2} \mathrm{O}, \mathrm{C}_{2} \mathrm{H}_{6}, \mathrm{C}_{3} \mathrm{H}_{6}, \mathrm{C}_{4} \mathrm{H}_{6}, \mathrm{C}_{3} \mathrm{H}_{8}, \mathrm{O}_{2}$ ), while the soot concentration in the exhaust gas was recorded by photoacoustic measurement (AVL Microsoot). For determining the EGR rate, the $\mathrm{CO}_{2}$ content in the intake manifold was measured with an infrared analyzer (AVL Sesam i60). Turbocharger speed was captured using inductive Micro Epsilon sensors.

An overview of the test bench layout is shown in Fig. 2, displaying the main variables measured by the corresponding measurement systems. In addition, several pressure and temperature sensors were installed at various positions, and the opening angles of all flaps and bypass valves were recorded. These additional measuring points are not displayed in the figure.

As a result of the modified firing order of the 3/4-cylinder concept, it was necessary to use a supplementary engine control unit (Vemac VeRa 3.0) in addition to the proprietary engine ECU. With this additional prototype ECU, it was possible to shift the injection signals according to the new firing order and the new ignition intervals of $240^{\circ} \mathrm{CA}$. For this purpose, the prototype ECU was inserted between the engine ECU and the injectors of the individual cylinders. By means 


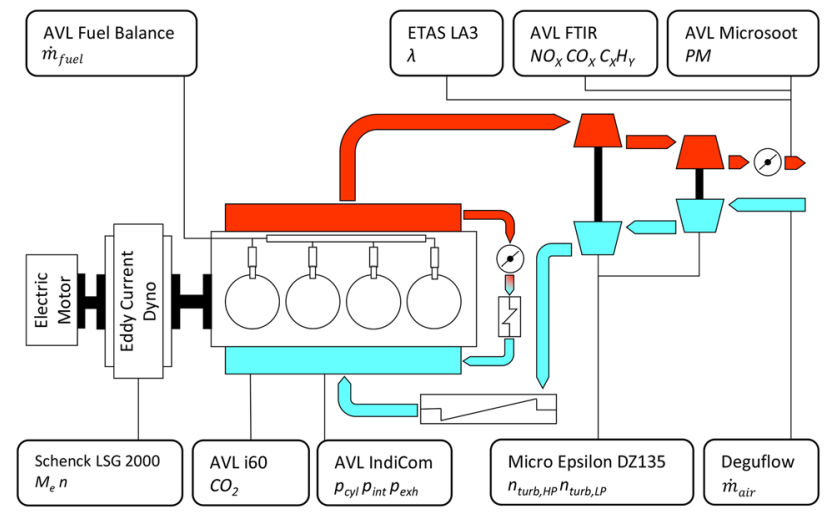

Fig. 2 Test bench set-up

of dummy loads for the injectors, the engine ECU could operate equivalent to regular engine operation, while in fact, the injection signals were shifted according to the new firing order, and the new injection signals were transmitted to the injectors. After an initial validation measurement, also the reference measurement of the base engine was carried out with the additional ECU mounted on the engine (however, without signal shift) to eliminate potential cross influences.

In 3-cylinder operation, the basic operating strategy was chosen as close to the series operation of the individual cylinders of the base engine as possible (i.e. based on cylinder load, not on overall engine load).

\section{Numerical models and procedure for loss analysis}

As a first step of the analysis process, a predictive onedimensional model of the engine was developed and calibrated using experimental data acquired during the reference measurements of the operating map of the base engine in series condition. The model was generated with the software tool GT Power (GT Suite). This model helped to predict the effects of various technical modifications to the base engine with good accuracy, e.g. the effect of modified valve lift curves and the new firing order of the 3/4-cylinder concept. The model also allows to determine the operating points of the turbochargers in the respective characteristic maps. The predictive model was primarily used for estimating the effect of various measures in the course of preliminary investigations, and also for the optimization of the concept based on the results of the experimental investigations.

Figure 3 shows a simplified representation of this model, with the four cylinders in the center, each equipped with an injector. Below the cylinders, the crank drive model of the engine is represented. The turbocharger models both consist of a turbine and a compressor, connected by a shaft.

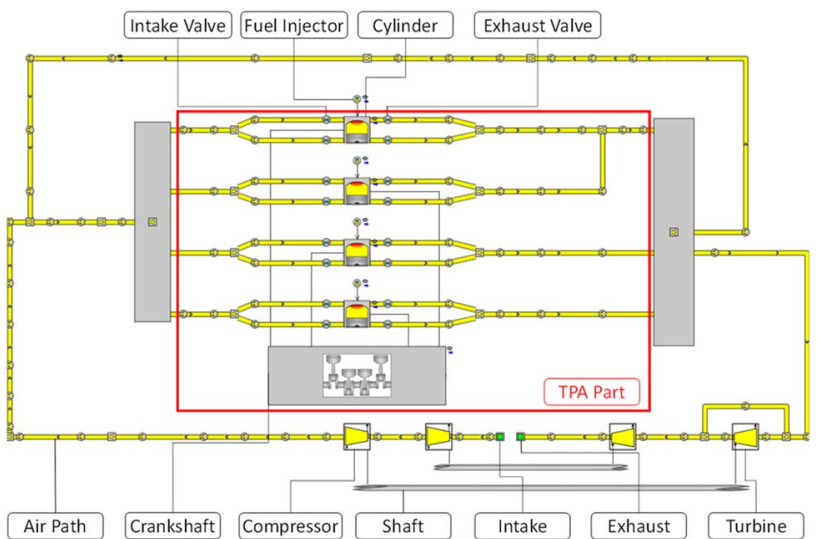

Fig. 3 Predictive GT Power model of the engine and simplified "TPA" sub-model (outlined in red)

The pipes of the air and exhaust path connect the cylinders with the intake manifold and the exhaust manifold, and further with the turbochargers and the other components of the intake and exhaust path and the environment. Each component shown in the figure was parameterized using data from the real engine in its original or modified version. In addition to geometric information, detailed technical data of all components were available for this purpose, including the discharge properties of the intake and exhaust ducts (from a flow bench test), the effective valve lift curves (acquired through laser-based valve lift measurement on a component test bench), and the turbine and compressor maps of the turbochargers. The injection characteristics of the injectors were also adjusted on the basis of data available from an injector test bench.

Based on the detailed model, a second model was derived to carry out a detailed loss analysis of the engine process. In this so-called "TPA" model ("three-pressure analysis"), starting from a constant volume cycle, the idealized assumptions of this process are successively replaced by real measurement data or detailed models [24]. The method applied here is largely based on the methodology described in [25, 26]. The TPA models were set up separately for all four cylinders of the engine and each includes the cylinder with the intake and exhaust ports up to the position of the pressure indication sensors during the experimental tests, with the boundary conditions being provided from these measurements (see Fig. 3).

In the left column of Table 2, the assumptions of the ideal constant volume process are listed. A process simulation with these assumptions delivers the ideal efficiency of the engine under test and represents the starting point of the further analysis. In the next step, the cycle is calculated again, replacing pure air as a working medium by the chemical composition of the charge derived from the measurement data. For this purpose, the components $\mathrm{O}_{2}, \mathrm{~N}_{2}$, "residual 
Table 2 Definition of the process efficiency losses used for the analysis

\begin{tabular}{|c|c|c|c|}
\hline Idealized assumption & Corrected assumption & Efficiency loss & Combined efficiency loss \\
\hline Working medium: pure air & Working medium: varying gas mixture & Actual charge & Real charge $\left(\Delta \eta_{\text {rch }}\right)$ \\
\hline Calorific values@ @ 1 bar/298 K & $\begin{array}{l}\text { Calorific values depending on real pressure } \\
\text { and temperature }\end{array}$ & Calorific properties & \\
\hline \multirow[t]{2}{*}{$\begin{array}{l}\text { Constant volume combustion (instantaneous } \\
\text { combustion @ TDC) }\end{array}$} & $\begin{array}{l}\text { Instantaneous combustion @ combustion } \\
\text { center }\end{array}$ & Combustion center & Real combustion $\left(\Delta \eta_{\mathrm{rc}}\right)$ \\
\hline & Burn rate as a function of CA & Real burn rate & \\
\hline Complete combustion & $\begin{array}{l}\text { Incomplete combustion (from exhaust } \\
\text { components) }\end{array}$ & Incomplete combustion & \\
\hline No wall heat transfer & $\begin{array}{l}\text { Wall heat transfer according to Hohenberg } \\
\text { model }\end{array}$ & Wall heat transfer & Wall heat transfer $\left(\Delta \eta_{\text {wht }}\right)$ \\
\hline Adiabatic expansion between EVO and BDC & Real process between EVO and BDC & Expansion & Real gas exchange $\left(\Delta \eta_{\text {rge }}\right)$ \\
\hline $\begin{array}{l}\text { Adiabatic compression between BDC and } \\
\text { IVC }\end{array}$ & Real process between BDC and IVC & Compression & \\
\hline \multirow[t]{2}{*}{ No pumping work } & $\begin{array}{l}\text { Gas exchange w/constant averaged intake } \\
\text { and exhaust pressure }\end{array}$ & Ideal pumping work & \\
\hline & $\begin{array}{l}\text { Gas exchange w/real intake and exhaust } \\
\text { pressure }\end{array}$ & Real pumping work & \\
\hline No friction & w/friction & Friction & Friction $\left(\Delta \eta_{\mathrm{fr}}\right)$ \\
\hline
\end{tabular}

gas" $\left(\mathrm{N}_{2}, \mathrm{CO}_{2}, \mathrm{H}_{2} \mathrm{O}\right)$ and "fuel" (diesel fuel, characterized by the values from a detailed analysis of the fuel used in the investigations, e.g. calorific value and density) are considered. The difference between the two efficiency values yields the efficiency loss due to actual charge. If in addition, the calorific values of the working medium are no longer assumed to be constant (with the values according to standard conditions), but dependent on the real thermodynamic boundary conditions as a function of the crank angle, the losses due to calorific properties can be derived. In the following, these two losses are combined and referred to as the efficiency loss due to real charge $\left(\Delta \eta_{\mathrm{rch}}\right)$.

Since in contrast to the constant volume process, the real center of combustion is usually not at top dead center (TDC), the cycle is recalculated in the next step with the actual center of combustion, but still assuming instantaneous combustion. This determines the efficiency loss due to the center of combustion. In the next process simulation, the real burn rate obtained from the measurements is used instead of instantaneous combustion. This gives the efficiency loss due to the real burn rate. On the basis of the species concentrations of $\mathrm{CO}$ and $\mathrm{H}_{2}$ in the exhaust, the completeness of combustion is evaluated, which in turn yields the efficiency loss due to incomplete combustion. However, this loss is almost negligible for diesel combustion due to the excess air in the combustion chamber. All three aforementioned losses are summarized as efficiency loss through real combustion $\left(\Delta \eta_{\mathrm{rc}}\right)$.

Wall heat losses cause a further loss of efficiency $\left(\Delta \eta_{\text {wht }}\right)$. The calculation of wall heat transfer is based on the approach developed by Hohenberg [27]. Due to the empirical nature of this approach, it is usually assumed that this partial loss is the least exact to be determined in comparison to the other losses. For this reason, wall heat transfer is adjusted in an iterative procedure using a so-called "heat transfer multiplier" to meet the brake efficiency determined experimentally after subtracting all losses from the ideal efficiency (see below for further explanation). However, the required adjustment by the wall heat multiplier should generally be only marginal.

The efficiency loss due to real gas exchange $\left(\Delta \eta_{\text {rge }}\right)$ consists of four further partial losses which are determined in separate process calculations. First, for the part of the expansion phase between exhaust valve opening (EVO) and bottom dead center (BDC), expansion is no more assumed to be adiabatic, but the measured pressure drop is used instead; this results in the so-called expansion loss. Similarly, in the compression phase between bottom dead center and intake valve closing (IVC), it is accounted for the fact that no compression will occur (compression loss). In two further steps, gas exchange is included in the analysis. This is done first by assuming ideal gas exchange, i.e. by applying constant values taken from the averaged pressures measured during gas exchange in the inlet port (for the intake stroke) and in the exhaust port (for the exhaust stroke). In this way, the so-called efficiency loss due to ideal pumping work is determined. Finally, the measured crank angle resolved pressure curves in the inlet and outlet are assumed for calculating the gas exchange, and from this, the loss through real pumping work is derived. The final efficiency loss component results from the friction of the engine $\left(\Delta \eta_{\mathrm{fr}}\right)$ and is determined by comparing 
indicated and brake effective power from the test bench measurement.

If all efficiency losses are subtracted from the efficiency of the ideal constant volume process, this initially results in a mathematically derived "brake" efficiency. Due to the modeling approaches (especially for wall heat transfer), this is not necessarily identical with the experimentally determined brake efficiency $\left(\eta_{b}\right)$. However, these deviations are usually almost negligible when working carefully [26], which also applies to the loss analysis calculations carried out in the context of the current work. To be able to use the well-established terms of brake and indicated efficiencyboth of which were determined experimentally during the test bench measurements- the wall heat loss was adjusted as described above by applying the "heat transfer multiplier" function provided in GT Power, so as to meet the measured brake efficiency also as the result of the loss analysis. Due to the deviations being only minimal, the multiplier only had to be adjusted very slightly in a narrow range close to 1 .

\section{Experimental results}

Figure 4 shows the characteristic map of measured brake specific fuel consumption (BSFC) of the modified engine in 3/4-cylinder operation. The minimum fuel consumption at the optimum point is $213.8 \mathrm{~g} / \mathrm{kWh}$, which is about $2 \%$ more than had been determined for the base engine (209.8 g/

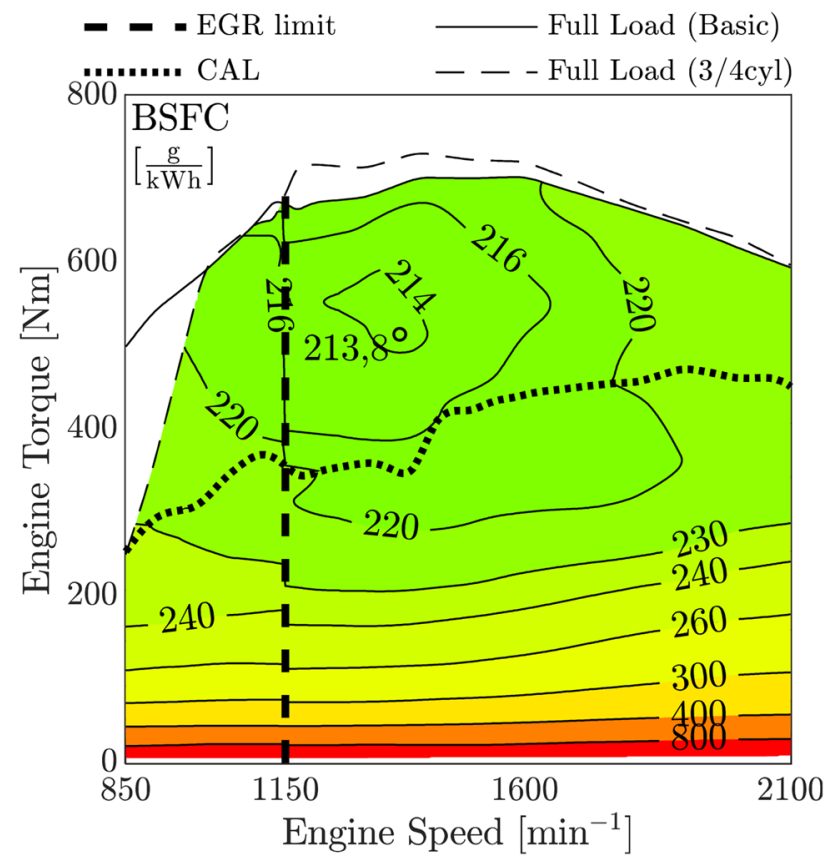

Fig. 4 Characteristic map of specific fuel consumption (BSFC), 3/4-cylinder operation
$\mathrm{kWh}$ ). The reasons for this deterioration will analyzed in detail in the following sections.

Furthermore, the so-called cylinder activation line (CAL) is plotted, which connects the optimum switching points between 3- and 4-cylinder operation (NB: the line has been smoothed slightly). Therefore, this line does not reflect the full-load curve of 3-cylinder operation, but results from a comparison of the two operating modes (3-cylinder mode and " $3+1$ " cylinder mode) with regard to optimum specific fuel consumption for each case. The "EGR limit" line indicates the speed limit above which the base engine is operated with EGR, and which was carried over to the modified engine. The full-load line of the modified engine differs slightly from the base engine. In the speed range below $1000 \mathrm{~min}^{-1}$, the maximum torque of the base engine could not be reproduced due to strong fluctuations in the engine operating behavior. Beyond $1000 \mathrm{~min}^{-1}$, stable high-load operation is possible and the maximum possible torque can be elevated due to the higher boost pressure generated by the turbocharger as a consequence of the double outlet pulse in " $3+1$ "-cylinder operation. In 3-cylinder operation, there were no significant variations in boost pressure in comparison to the base engine.

In Fig. 5, the difference in specific fuel consumption of the reference engine compared to the 3/4-cylinder concept is plotted. The most significant fuel economy benefit was realized in the low-load region, and especially at elevated engine speeds. In 3-cylinder operation, BSFC could be reduced by up to $18 \%$ compared to the standard 4 -cylinder

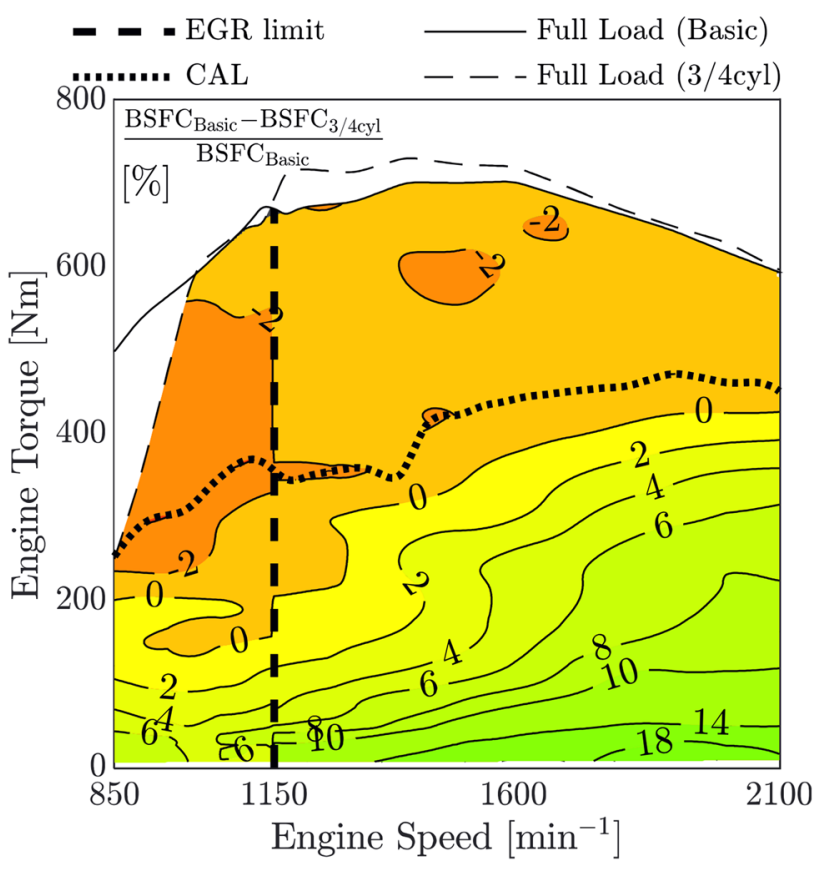

Fig. 5 Differential map of specific fuel consumption BSFC, base engine vs. 3/4-cylinder configuration 
mode. In typical real engine operating points at part load, however, the benefit was significantly lower, with relative improvements in the range from 0 to approx. $8 \%$. As could be expected, the consumption benefit decreases with increasing engine load. In a narrow range between the $0 \%$ isoline and the CAL, fuel consumption in 3-cylinder operation is higher than in basic operation. This is due to the fact that in this range, the specific fuel consumption in 3-cylinder operation is lower than in " $3+1$ "-cylinder operation, but higher than in 4-cylinder operation of the base engine. In almost the entire operating range of " $3+1$ "-cylinder operation, a consumption penalty of approx. $2 \%$ compared to the 4-cylinder operation of the base engine was found. Thus, the consumption benefit at part load achieved with this concept is associated with slight disadvantages in high-load operation. Depending on the real operating profile, a significant reduction of the effective BSFC benefit of the concept may, therefore, result from this behavior.

Besides the fuel economy effects, also the influence on the exhaust emissions caused by the modifications was assessed in both 3-cylinder and " $3+1$ "-cylinder operation. Major differences could be observed in the speed region directly above the "EGR limit", i.e. when the base engine is run with considerable amounts of EGR recirculated through the high-pressure EGR loop. Due to the load point shift, however, the pressure difference between the exhaust and the intake manifold is no longer sufficient for the recirculation of the required amounts of exhaust in the high-load region of 3-cylinder operation (thus, the medium load region of the engine). Consequently, $\mathrm{NO}_{\mathrm{x}}$ emission increased significantly in the medium load region up to around $1500 \mathrm{~min}^{-1}$, while particulate emission dropped substantially, on the other hand, following the typical $\mathrm{NO}_{x}$-particulate trade-off behavior. In an attempt to increase the EGR rate beyond the limits of the external high-pressure loop, the valve train variabilities were used to recirculate EGR directly into the combustion chamber by rebreathing through a second-exhaust valve opening during aspiration. The combination of both external and internal EGR allowed to increase the EGR rate significantly; however, the $\mathrm{NO}_{x}$-particulate trade-off deteriorated due to the increased in-cylinder temperature caused by direct rebreathing from the exhaust. It was, therefore, concluded that the EGR strategy should be completely revised in a further optimization step (potentially including the turbocharger layout, see Sect. 6). Potential measures to allow more EGR in the critical mid-load region could be low-pressure or "mixed" (high pressure to low pressure) EGR. However, it needs to be underlined that in the region of maximum fuel economy benefit, the emission level is comparable to the base engine. To avoid secondary effects from variations in EGR level, an engine speed of $2000 \mathrm{~min}^{-1}$ was chosen for the loss analysis in the following section. At the operating points studied at this engine speed, the EGR rate could be adjusted to comparable levels for the 3/4-cylinder engine as for the base engine, resulting also in very similar levels of $\mathrm{NO}_{x}$ and $\mathrm{PM}$.

$\mathrm{HC}$ and $\mathrm{CO}$ emissions, on the other hand, were significantly reduced in 3-cylinder operation. This may at least partly be attributed to the reduced EGR rate, of course. As also the exhaust temperature is increased in 3-cylinder operation, additional positive effects from increased post-oxidation may occur. However, $\mathrm{HC}$ and $\mathrm{CO}$ emissions are already at a very low level for the base engine and the improvement is, therefore, not very relevant for practical operation.

The increased exhaust temperature due to the load point shift might nonetheless produce positive effects on the exhaust aftertreatment system. Figure 6 compares the isolines of $250{ }^{\circ} \mathrm{C}$ exhaust temperature for the base engine and the 3/4-cylinder concept. This temperature level is assumed to correspond to the light-off temperature of the exhaust aftertreatment system, thus corresponding both to DOC light-off and the limit for passive regeneration of the DPF. Moreover, it can be assumed that at this temperature, there is no more risk of crystallization of urea at the mixer of the SCR system.

While cold-start light-off additionally depends on the overall exhaust enthalpy-which is not increased by the load point shift-the exhaust temperature level is of primary importance for avoiding the cooling of the exhaust aftertreatment below light-off in low-load operation [28]. As obvious from the figure, the $250^{\circ} \mathrm{C}$ isoline is reached at significantly lower load in 3/4-cylinder operation. Hence, the load point switch may contribute to improved real-world emission behavior and reduce the need for catalyst warming measures at low load.

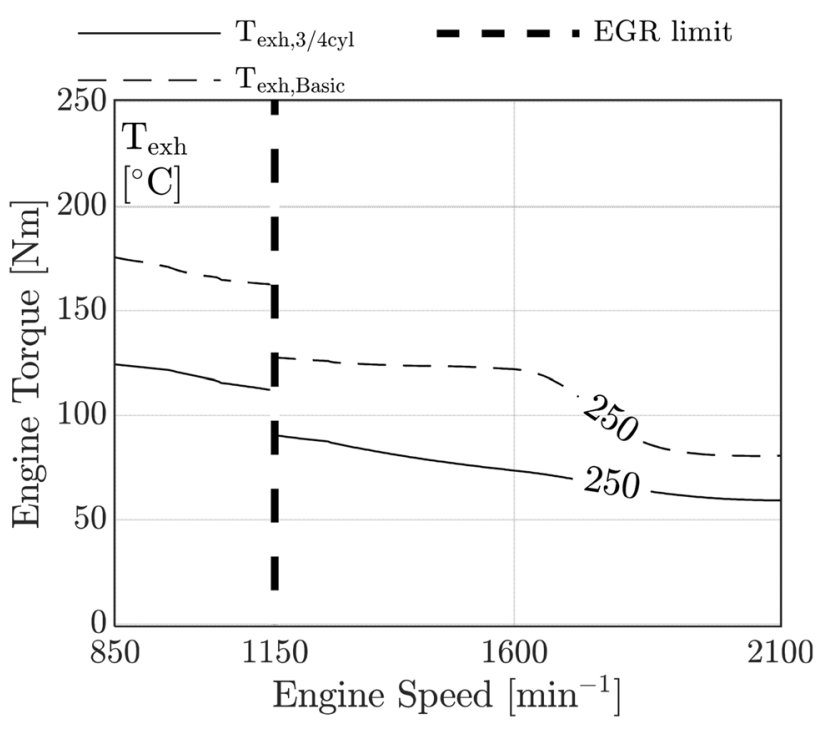

Fig. 6 Comparison of exhaust temperature $/ 250{ }^{\circ} \mathrm{C}$ isolines, base engine vs. 3/4-cylinder configuration 


\section{Loss analysis and discussion}

To analyze the causes of the both the fuel consumption advantages and disadvantages of the 3/4-cylinder concept, a detailed cylinder-selective loss analysis was carried out. For this purpose, the 1D simulation model of the engine described above was parameterized using the parameter settings of the experimental investigations (e.g. injection times) as well as the pressure traces from the indication measurement, the recorded temperatures and the respective exhaust gas composition. By repeated process calculation according to the method described in Sect. 3, the individual partial efficiency losses could be quantified separately for each cylinder and for all of the load points measured during the experimental investigations.

Since the loss analysis was carried out cylinder-selective, deviations between the cylinders are also revealed in the results. Figure 7 shows the results of the loss analysis at an engine speed of $2000 \mathrm{~min}^{-1}$ for the reference measurement of the base engine and for the 3/4-cylinder operation of the modified engine. Each of the eight figures consists of 16 separate loss analyses. The sampling points were selected at intervals of $50 \mathrm{Nm}$. Looking at the upper row of figures, it can be seen that the individual losses of all cylinders of the reference engine exhibit almost the same pattern. This points to a good mixing of the externally recirculated exhaust gas, as well as a uniform distribution of the aspirated air to the four cylinders. In the low-load range, wall heat losses and efficiency losses due to real gas exchange are predominant. With increasing load, the efficiency losses due to real charge and real combustion become increasingly significant and finally dominate all of the other losses.

The loss analysis of the 3/4-cylinder concept is split into 3-cylinder and " $3+1$ " cylinder operation. Since at this engine speed, 3-cylinder operation produces a lower specific fuel consumption than " $3+1$ " cylinder operation up to an engine load of $450 \mathrm{Nm}$, " $3+1$ " cylinder operation is only relevant from the next higher load point measured $\left(2000 \mathrm{~min}^{-1} / 500 \mathrm{Nm}\right)$. Consequently, the loss analysis of cylinder 1 is only displayed starting from this load. For comparison, the curve of brake efficiency $\eta_{b}$ of the base engine is shown as a dashed white line in the diagrams of 3/4-cylinder operation.

From this figure, the improvement in brake efficiency of the three active cylinders of the 3/4-cylinder engine compared to base operation is clearly visible at part load. Especially the loss due to real gas exchange is significantly lower than in the reference engine. This results in higher brake efficiency for the 3/4-cylinder concept at low-tomedium loads compared to the base engine. For " $3+1$ " cylinder operation, it is evident that the gas exchange losses of cylinders 1 and 4 are higher than those of cylinders 2 and 3. This results in brake efficiency dropping below the value of the base engine in this operating region. To clarify these effects, two load points will be studied in more detail below: $2000 \mathrm{~min}^{-1} / 200 \mathrm{Nm}$ (in 3-cylinder operation) and $2000 \mathrm{~min}^{-1} / 500 \mathrm{Nm}$ (in " $3+1$ " cylinder operation).

Figure 8 shows an efficiency analysis at $2000 \mathrm{~min}^{-1}$ and $200 \mathrm{Nm}$ for cylinder 4 in 3-cylinder operation compared to the same cylinder in base operation. The five partial losses
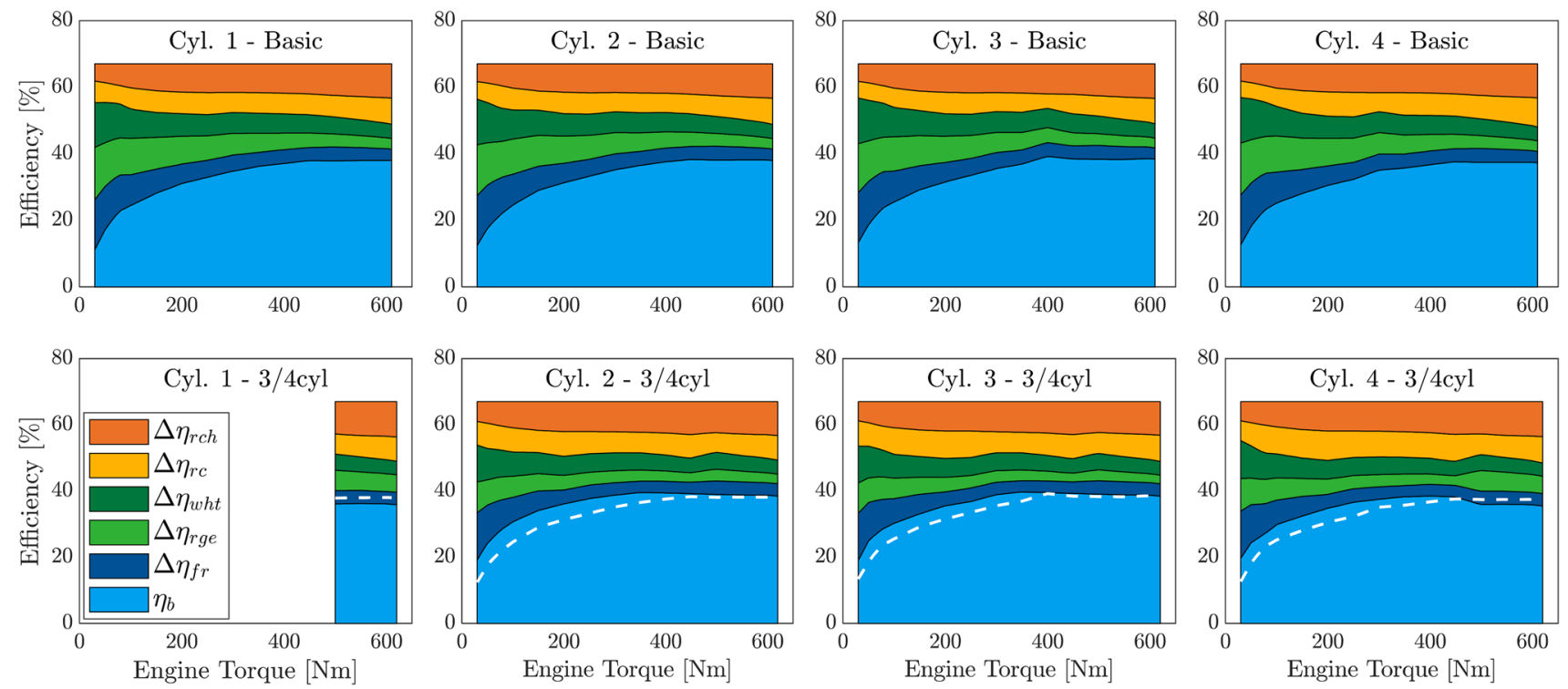

Fig. 7 Cylinder-selective loss analyses at $n=2000 \mathrm{~min}^{-1}$; upper row: base engine, lower row: 3/4-cylinder operation (white dashed line: brake efficiency of base engine) 


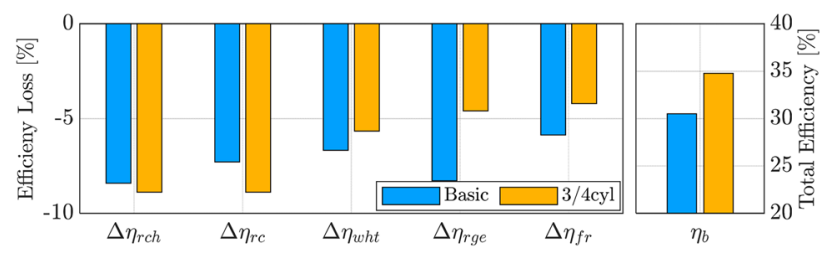

Fig. 8 Efficiency loss analysis at $2000 \mathrm{~min}^{-1} / 200 \mathrm{Nm}$ in [\%], cylinder 4

are plotted on the left, the resulting brake efficiency is displayed on the right.

Although the losses due to real charge and real combustion are higher in the 3/4-cylinder concept, this is overcompensated by the lower losses due to wall heat transfer, real gas exchange and friction. This results in a brake efficiency of $34.8 \%$ for cylinder 4 in 3/4-cylinder operation compared to $30.5 \%$ for base operation. The losses due to real combustion are higher in 3-cylinder operation, as the mass of fuel injected per cylinder increases, thus also increasing the duration of combustion. As a result, the pressure trace moves further away from the ideal process, and the corresponding efficiency loss increases.

In this diagram, the wall heat losses in 3-cylinder operation appear to be lower than those of the base engine. However, the heat flux here is only smaller by percentage of cylinder load, while the absolute heat flux of cylinder 4 is actually larger. To illustrate this, Fig. 9 shows the losses expressed as mean effective pressure. This clarifies that the wall heat losses of cylinder 4 in 3-cylinder operation are slightly higher than in base operation. However, the wall heat losses of the deactivated cylinder are negligible, so that the wall heat transfer of the entire engine in 3-cylinder operation is actually lower than in base operation. In the simulation, the overall heat transfer in base operation amounted to $28.7 \mathrm{~kW}$, compared to only $23.2 \mathrm{~kW}$ for 3-cylinder operation. Thus, an additional reason for the reduction in fuel consumption can be found in the reduced overall losses due to wall heat transfer. Figure 9 also shows the higher BMEP of cylinder 4 in 3/4-cylinder operation compared to the base engine, which is due to the deactivation of cylinder 1 in this operating range.

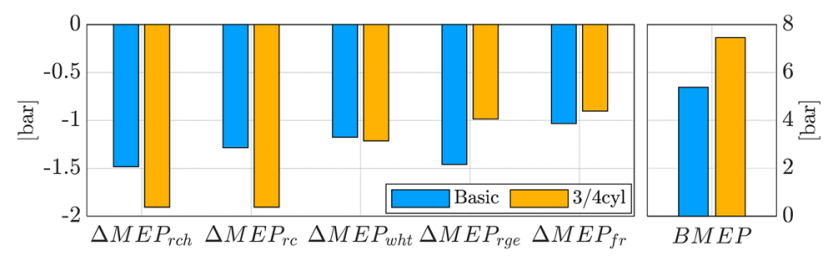

Fig. 9 Efficiency loss analysis at $2000 \mathrm{~min}^{-1} / 200 \mathrm{Nm}$ expressed as mean effective pressure in [bar], cylinder 4
However, the main reason for the improvement in fuel consumption can be found in the reduced gas exchange loss (see Figs. 8 and 9). The reasons for this will be analyzed in more detail below.

In both operating modes, a mean absolute boost pressure of approx. 1.7 bar was measured (basic mode: 1.70 bar, 3-cylinder mode: 1.74 bar). However, the pressure in the exhaust manifold differs significantly. Figure 10 shows both the indicated and the averaged exhaust backpressure for the two operating modes. The pressure variations in the manifold are more pronounced in 3-cylinder operation than in base operation, as both the firing intervals and the mass discharged per cylinder are increased. The averaged pressure of 2.2 bar is nevertheless significantly lower than in the reference measurement of the base engine ( $2.8 \mathrm{bar}$ ).

In Fig. 11, the dashed line indicates the gas exchange loop of the fourth cylinder in the reference measurement, while the solid line represents the 3-cylinder mode. Using the BDC-to-BDC method, the gas exchange losses can be quantified at -1.4 bar in basic operation, and at -0.9 bar in 3-cylinder operation. This is illustrated very clearly in the figure, since the enclosed area of the gas exchange loop in 3-cylinder operation is significantly smaller for the base engine. Accordingly, the gas exchange losses are lower due to the reduced backpressure. In addition, the gas exchange work of the first cylinder is completely eliminated.

Figure 12 displays the efficiency analysis of the fourth cylinder at an operating point at $2000 \mathrm{~min}^{-1}$ and $500 \mathrm{Nm}$, which is in the operating range of " $3+1$ " cylinder operation. The brake efficiency in " $3+1$ " cylinder operation is $35.9 \%$, which is $1.5 \%$ lower than in basic operation. The graph shows that the reduced brake efficiency is mainly due to the increased gas exchange work. It should be noted that the cylinder studied here (cylinder 4) is operated in parallel to

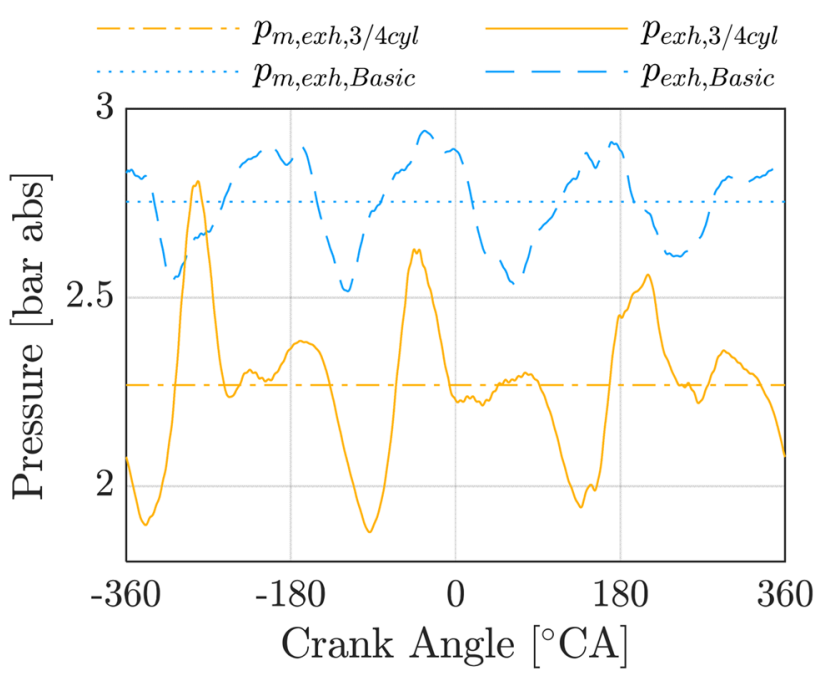

Fig. 10 Exhaust backpressure at $2000 \mathrm{~min}^{-1} / 200 \mathrm{Nm}$ 


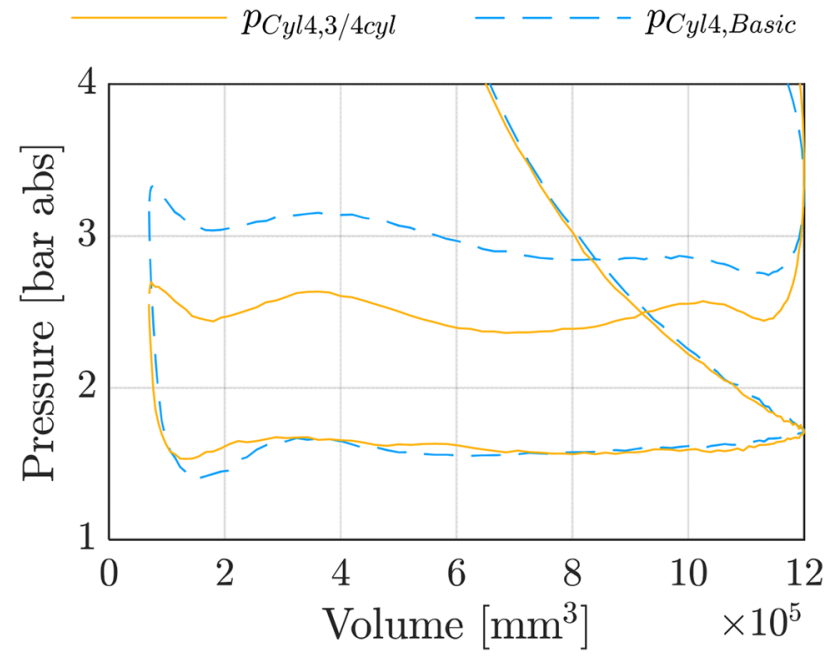

Fig. 11 Gas exchange loop of cylinder 4 at $2000 \mathrm{~min}^{-1} / 200 \mathrm{Nm}$

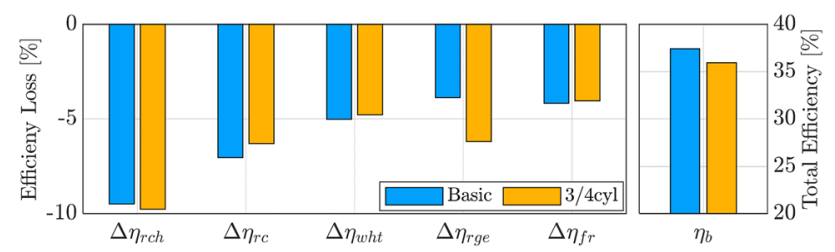

Fig. 12 Efficiency loss analysis at $2000 \mathrm{~min}^{-1} / 500 \mathrm{Nm}$, cyl. 4

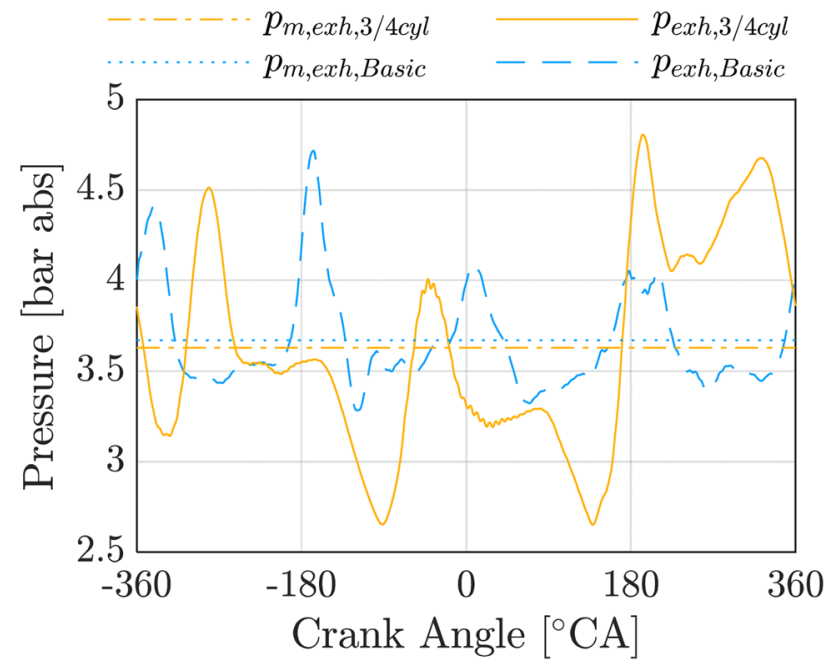

Fig. 13 Exhaust backpressure at $2000 \mathrm{~min}^{-1} / 500 \mathrm{Nm}$

cylinder 1 in " $3+1$ " cylinder operation. The effects resulting from this will be examined in more detail in the following.

The indicated pressure traces for the outlet manifold (Fig. 13) result in approximately the same average pressure (base operation: 3.67 bar/" $3+1$ " cylinder operation: 3.65 bar). Nevertheless, the gas exchange work of the fourth (and also of

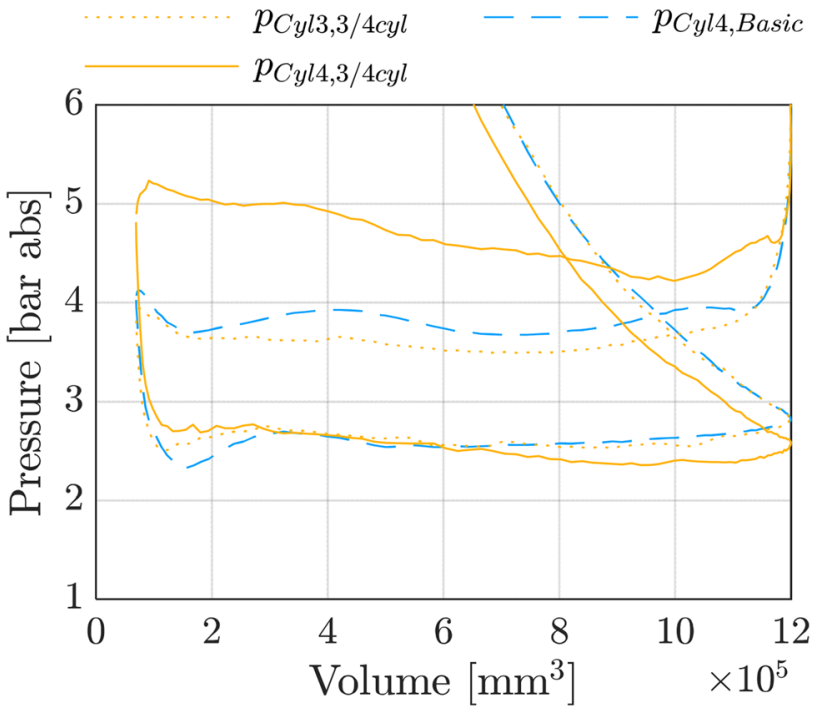

Fig. 14 Gas exchange loop of cylinder 4 at $2000 \mathrm{~min}^{-1} / 500 \mathrm{Nm}$

the first) cylinder is significantly increased due to the simultaneous exhaust stroke.

The gas exchange loops of the fourth cylinder in both base and " $3+1$ " cylinder operation are plotted in Fig. 14. In addition, the gas exchange loop of the third cylinder in " $3+1$ " cylinder mode is shown. This comparison clearly illustrates the strong divergence between the cylinders in " $3+1$ " cylinder operation of the 3/4-cylinder concept. Although the effective gas exchange work of cylinders 2 and 3 in " $3+1$ " cylinder mode is slightly lower than in basic operation, the average gas exchange losses of all four cylinders are higher. In the reference measurement, -1.2 bar was required on average for the gas exchange work of each cylinder, with only minor variations. In " $3+1$ " cylinder operation, the gas exchange work of cylinders 1 and $4(-2.1$ bar) is almost twice as high as for the adjacent cylinders 2 and 3 ( -1.1 bar). Figure 14 illustrates the size of the enclosed areas of the gas exchange loops. The increased backpressure is also evident from Fig. 13. The outlet valves of cylinders 1 and 4 open simultaneously and cause the pressure pulse shown in the figure, which results in a mutual obstruction of the exhaust processes of the two cylinders. These effects were observed in a similar way in the entire operating range of the " $3+1$ " cylinder mode, and are, therefore, the primary cause of the experimentally observed fuel consumption disadvantage in this region of the operating map.

\section{Conclusion and analysis of further steps for concept optimization}

The above analysis showed that the advantages in 3-cylinder operation can be attributed not only to reduced friction and wall heat losses, but above all to improved gas 
exchange. This is due in particular to the reduced cross influence between the exhaust processes of the individual cylinders and to the generally reduced mean exhaust backpressure. As a result, the gas exchange loop is significantly reduced. However, the opposite is true for the 4-cylinder mode of the 3/4-cylinder concept; here, cylinders 1 and 4 interfere with each other and the mean exhaust backpressure during the exhaust stroke increases significantly.

To counteract this phenomenon, the exhaust events of cylinders 1 and 4 should be separated from each other to a certain extent if possible. The first approach was to find a simple solution to achieve this separation purely by valve control, e.g. by opening the exhaust valves of cylinder 1 slightly earlier and those of cylinder 4 slightly later, thus offset in phase. In this way, it was intended to reduce the pressure peak occurring at simultaneous opening of the exhaust valves of cylinder 1 and cylinder 4 . Various offsets up to $\pm 20^{\circ} \mathrm{CA}$ were studied by $1 \mathrm{D}$ simulation. For this purpose, the existing predictive simulation model (see Sect. 3), which was validated in base and 3/4-cylinder operation, was modified with respect to the offsets in exhaust valve timing as described above, and simulation runs were performed for the operating point at $2000 \mathrm{~min}^{-1} / 500 \mathrm{Nm}$. However, no improvement in overall efficiency could be achieved for any of the offset variants mentioned above, which was mainly due to additional expansion losses of cylinder 1 (with the exhaust valves opening earlier) and also increased exhaust work for cylinder 4 due to its retarded exhaust opening.

As another alternative, cylinder 1 could be operated not in parallel to cylinder 4, but with an offset of $360^{\circ} \mathrm{CA}$. For this purpose, the cams would have to be realigned on the camshaft and the injection signal shifted accordingly, while the crankshaft layout could be left unchanged. This modification was also studied by $1 \mathrm{D}$ simulation. The calculation results were evaluated according to the same logic with regard to partial losses as the experimental results discussed in Sect. 5.

Figure 15 shows the plots of pressure versus crank angle for $360^{\circ} \mathrm{CA}$ offset of cylinder 1 with respect to cylinder 4 , compared to the situation as studied before in Sect. 5, thus with cylinder 1 and 4 acting in parallel. From the figure, it is obvious that with the new firing order, cylinder 1 falls directly between cylinder 2 and 3, thus influencing both of these cylinders, which will also reflect in the loss analysis discussed in the following.

In Fig. 16, the results of the loss analysis of cylinder 1 to 4 for the $360^{\circ} \mathrm{CA}$ offset at $2000 \mathrm{~min}^{-1} / 500 \mathrm{Nm}$ in 3/4-cylinder operation are compared to the results of the loss analysis for the operation without offset (thus as discussed in Sect. 5, but using simulation instead of experimental data). From this analysis, it becomes obvious that the modification had a very positive effect on the gas exchange of cylinder 4 , resulting
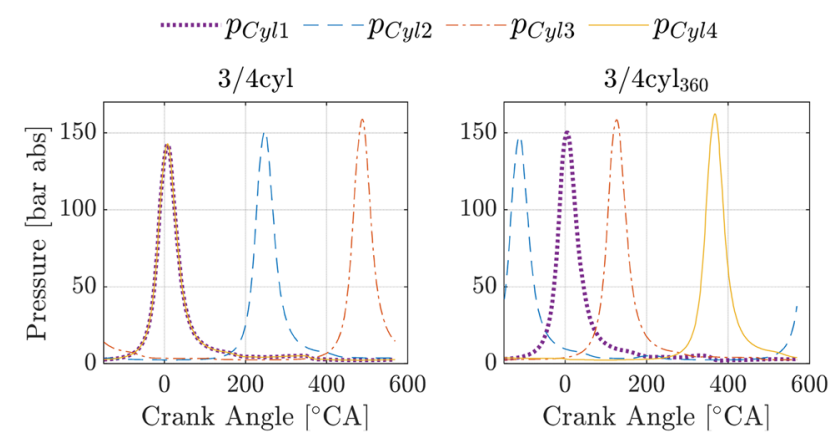

Fig. 15 Cylinder pressure traces of all four cylinders at $2000 \mathrm{~min}^{-1} / 500 \mathrm{Nm}$ - comparison of $360^{\circ} \mathrm{CA}$ offset of cyl. 1 and 4 $\left(3 / 4\right.$ cyl $\left._{360}\right)$ vs. no offset (3/4-cyl)
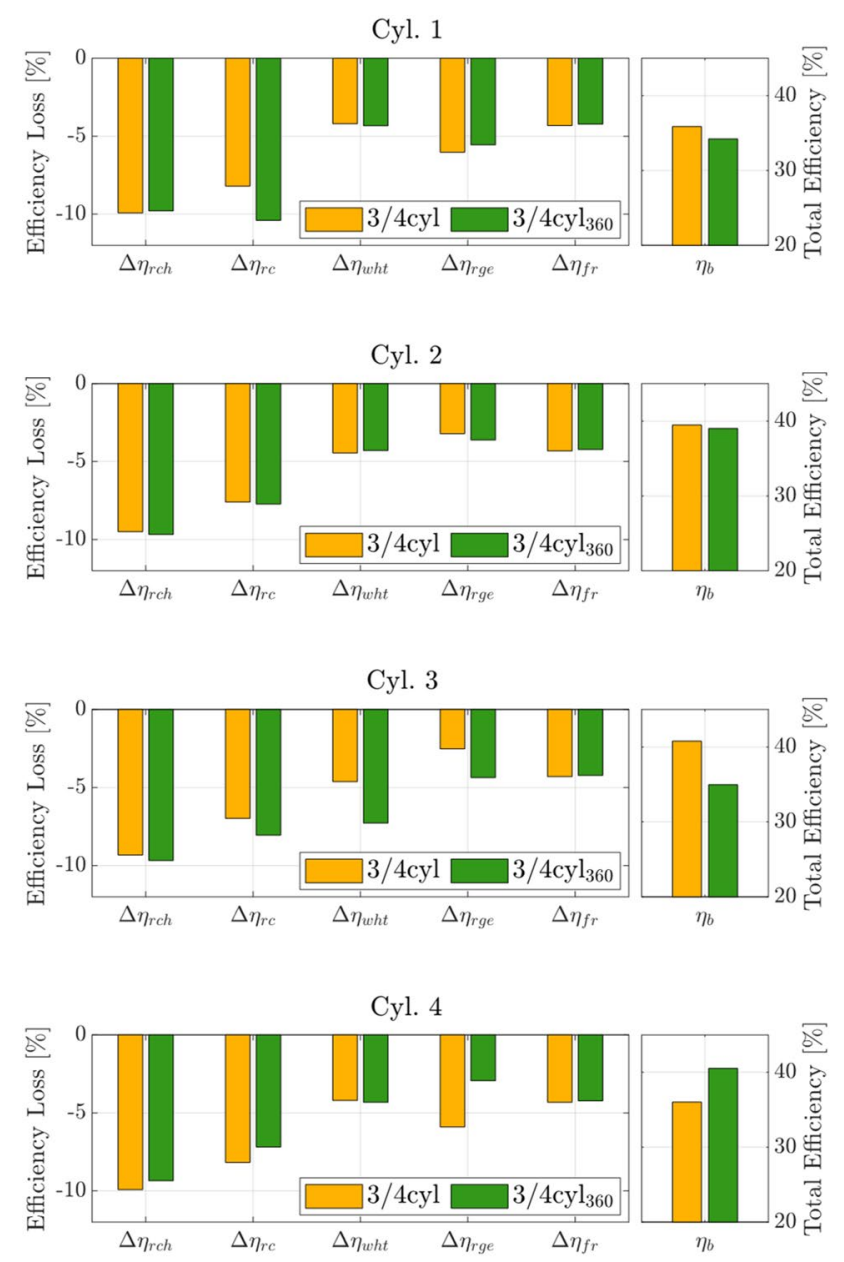

Fig. 16 Efficiency loss analysis at $2000 \mathrm{~min}^{-1} / 500 \mathrm{Nm}$ (3/4-cyl. operation); comparison of $360^{\circ} \mathrm{CA}$ offset of cyl. 1 and 4 vs. no offset

in the respective losses being more than halved. As also the losses due to real charge and real combustion are reduced, the overall efficiency of cylinder 4 is significantly improved.

However, the opposite is true for all of the other cylinders, including cylinders 2 and 3 , which both suffer from 
increasing gas exchange losses. Cylinders 1 and 3 also exhibit higher losses due to real combustion. These losses can be attributed to the interaction of these three cylinders during gas exchange, which also includes the intake process. This is due to the new firing order with cylinder 1 being fired in between cylinders 2 and 3 .

The resulting gas exchange loops of cylinders $1-4$ are displayed in Fig. 17. While the gas exchange loop of cylinder 4 has been reduced significantly, both cylinder 1 and 2 show an increase of in-cylinder pressure in the second half of the exhaust stroke due to increased backpressure caused by the next cylinder (cyl. 3 and 1, respectively) starting its exhaust process. Cylinder 1 is subject to particularly unfavorable boundary conditions, as already at exhaust valve opening, the backpressure is increased by the exhaust process of cylinder 2. Additionally, its aspiration process is also competing with cylinder 2 , which is the reason for its still comparatively high losses due to real gas exchange.

On the whole, there was no significant change-neither positive nor negative-in overall efficiency of the entire engine resulting from the $360^{\circ} \mathrm{CA}$ offset of cylinder 1 , according to the simulation. It was, therefore, concluded that by pure variation in the exhaust phasing or in the firing order, the problem of cylinder-to-cylinder interaction in gas exchange cannot be solved for this concept. In continuation to the study presented here, it is, therefore, planned to evaluate other ways of avoiding interaction between the cylinders, e.g. by modifying the exhaust and/or the intake duct layout. As such measures will also have an impact on the turbocharger configuration, a much more extensive study is required for these concepts.

In an attempt to simplify the concept, on the other hand, experimental investigations with different forms of cylinder deactivation were carried out which would require less
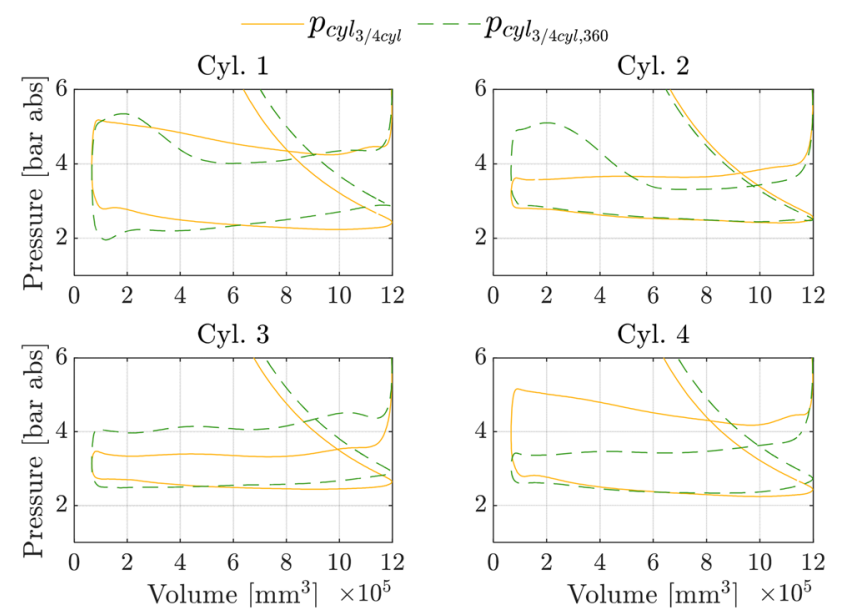

Fig. 17 Efficiency loss analysis at $2000 \mathrm{~min}^{-1} / 500 \mathrm{Nm}$ (3/4-cyl. operation); comparison of $360^{\circ} \mathrm{CA}$ offset of cyl. 1 and 4 vs. no offset modifications to the base engine. As one variation, the engine map was measured with deactivation of cylinder 1 and only three active cylinders (2, 3 and 4$)$ using the original crankshaft, i.e. with uneven firing order. As in 3/4-cylinder operation, an advantage was found in specific fuel consumption compared to four active cylinders. However, due to the irregular firing order, the advantage was 2 to $4 \%$ lower than in the 3-cylinder mode of the 3/4-cylinder concept throughout the entire operating region of this mode. As a result, the useful effective operating range for cylinder deactivation is also reduced considerably, so that such a concept no longer provides a reasonable cost-to-benefit ratio. However, the well-known deactivation of two out of four cylinders can still be a useful option for some applications, although the potential strongly depends on the operating profile of the engine and is primarily effective for very low-load operation schemes of the engine. This variant was already studied earlier using a different test engine (also a commercial vehicle diesel engine), but only delivered a comparatively small useful operating range with cylinder deactivation [29]. For the tractor application intended here, the 3/4-cylinder concept clearly delivers the best overall fuel economy potential despite its limitations.

\section{Summary and outlook}

The experimental investigation of the so-called " $3 / 4$-cylinder" concept described in the introduction, which is an engine concept with "real" 3-cylinder operation at part load and the first cylinder operating in parallel to the fourth cylinder at full load, revealed some promising potential for fuel economy improvement in the low-to-medium load range. However, this is partly compromised by disadvantages at high-load operation. A detailed study based on loss analysis and 1D simulation showed that the advantages in 3-cylinder operation can be attributed not only to reduced friction and wall heat losses, but above all to improved gas exchange. The reasons for this can be found in particular in the reduced cross influence of the exhaust processes of the individual cylinders and in the generally lower mean exhaust backpressure. As a result, the gas exchange work in 3-cylinder operation is significantly reduced. The opposite effect can be observed in 4-cylinder operation of the 3/4-cylinder concept, though. Here, cylinders 1 and 4 affect each other considerably due to the simultaneous exhaust stroke, leading to an increase in the average backpressure during the exhaust stroke of these cylinders.

Based on this finding, several variations of the original 3/4-cylinder concept were studied by 1D simulation. This included both slight offsets in exhaust phase between the two interfering cylinders 1 and 4, as well as an offset of $360^{\circ} \mathrm{CA}$ of the entire process of cylinder 1 with respect to 
cylinder 4. However, all of these variations were not successful in improving fuel economy in 4-cylinder operation. It was concluded that much more complex modifications to the exhaust and/or intake ducts, in combination with a modified turbocharger layout would be necessary to find a solution to this disadvantage of the concept. Such investigations are planned for a future, extended simulation study.

Attempts to simplify the initial concept by only deactivating one cylinder of a standard 4-cylinder engine were not successful, either, as the fuel economy potential would be strongly reduced due to the considerably smaller resulting effective operating range in deactivated mode. Therefore, such a concept no longer offers a reasonable cost-to-benefit ratio, as it would also require additional measures to avoid excessive vibrations. In contrast, the more common deactivation of two out of four cylinders could still be useful depending on the operating profile of the engine. Generally, such concepts are primarily effective for very low-load operation profiles. For the application in a typical tractor drive considered here, however, the 3/4-cylinder concept could represent a reasonable approach and should provide a significant reduction of real-world fuel consumption.

Acknowledgements Major parts of the work presented here were carried out in the context of the project "Highly Efficient Diesel Engine Concept" ("HDMK", Funding Code: 19U15003A), funded by the Federal Ministry of Economic Affairs and Energy with TÜV Rheinland as project management organization. The authors would like to express their gratitude for this funding.

Furthermore, the authors would like to thank the project partner John Deere GmbH \& Co. KG for providing the base engine, as well as for the comprehensive support throughout the project.

Funding Open Access funding provided by Projekt DEAL.

\section{Compliance with ethical standards}

Conflict of interest All authors declare that there is no conflict of interest.

Open Access This article is licensed under a Creative Commons Attribution 4.0 International License, which permits use, sharing, adaptation, distribution and reproduction in any medium or format, as long as you give appropriate credit to the original author(s) and the source, provide a link to the Creative Commons licence, and indicate if changes were made. The images or other third party material in this article are included in the article's Creative Commons licence, unless indicated otherwise in a credit line to the material. If material is not included in the article's Creative Commons licence and your intended use is not permitted by statutory regulation or exceeds the permitted use, you will need to obtain permission directly from the copyright holder. To view a copy of this licence, visit http://creativecommons.org/licenses/by/4.0/.

\section{References}

1. Fortnagel, M., Schommers, J., Clauss, R., Glück, R., et al.: Der neue Mercedes-Benz 12-zylinder-motor mit zylinderabschaltung. MTZ Motortechnische Zeitschrift 61, 280 (2000)

2. Neugärtner, J., Scholz, A., Schurr, A., Günthner, M. et al.: Load point shifting for Diesel engines - potentials for passenger car and truck engine applications. In: Liebl J., Beidl C. (eds) Internationaler Motorenkongress 2017. Proceedings, pp. 43-61. Springer Vieweg, Wiesbaden (2017). DOI: 10.1007/978-3-658-17109-4_6

3. Gosala, D.B., Shaver, G.M., McCarthy, J.E., Lutz, T.P.: Fuel-efficient thermal management in diesel engines via valvetrain-enabled cylinder ventilation strategies. Int. J. Engine Res. (2019). https:// doi.org/10.1177/1468087419867247

4. Abthoff, J., Schuster, H., Wollenhaupt, G.: Ein Motorenkonzept mit Zylinderabschaltung und seine Verbrauchsreduzierung (in German). MTZ Motortechnische Zeitschrift 41 (1980)

5. Middendorf, H., Theobald, J., Lang, L., Hartel, K.: The 1.41 TSI gasoline engine with cylinder deactivation. MTZ Worldw 73, 4-9 (2012). https://doi.org/10.1365/s38313-012-0147-0

6. Eichler, F., Gindele, J., Hart, M., Ramsteiner, T. et al.: The New AMG 5.51 V8 naturally aspirated engine with cylinder shut-off. In: Proceedings of the 20th Aachen Colloquium Automobile and Engine Technology (2011)

7. Allen, C.M., Gosala, D.B., Shaver, G.M., McCarthy, J.: Comparative study of diesel engine cylinder deactivation transition strategies. Int. J. Engine Res. 20(5), 570-580 (2019). https://doi. org/10.1177/1468087418768117

8. Küpper, K., Linsel, J., Pingen, B., Weber, C.: Cylinder deactivation for three-cylinder engines. MTZ Worldw 77, 46-51 (2016). https://doi.org/10.1007/s38313-016-0132-0

9. Parker, M.C., Jiang, C., Butcher, D., Spencer, A., et al.: Impact and observations of cylinder deactivation and reactivation in a downsized gasoline turbocharged direct injection engine. Int. J. Engine Res. (2019). https://doi.org/10.1177/1468087419882817

10. Flierl, R., Hannibal, W., Schurr, A., Neugärtner, J.: Turbocharged three-cylinder engine with activation of a cylinder. MTZ Worldw 75, 22-27 (2014). https://doi.org/10.1007/s38313-014-0158-0

11. Buitkamp T.: Potenziale eines Dieselmotors mit variablem Ventiltrieb und Zylinderzuschaltung in einem Traktor (in German). Ph.D. Thesis, TU Berlin (2019)

12. Fujiwara, M., Kumagai, K., Segawa, M., Sato, R. et al.: Development of a 6-cylinder gasoline engine with new variable cylinder management technology. SAE Technical Paper 2008-01-0610 (2008). DOI: 10.4271/2008-01-0610

13. Faust, H., Scheidt, M.: Potentials and constraints of cylinder deactivation in the powertrain. MTZ World 77, 72-77 (2016). https:// doi.org/10.1007/s38313-016-0046-X

14. Schamel, A., Scheidt, M., Weber, C., Faust, H.: Is cylinder deactivation a viable option for a downsized 3-cylinder engine? In: Proceedings of the 36th International Vienna Engine Symposium, Vienna (2015)

15. Serrano, J., Routledge, G., Lo, N., Shost, M., et al.: Methods of evaluating and mitigating $\mathrm{NVH}$ when operating an engine in dynamic skip fire. SAE Int. J. Engines 7(3), 1489-1501 (2014). https://doi.org/10.4271/2014-01-1675

16. Eisazadeh-Far, K., Younkins, M.: Fuel Economy gains through dynamic-skip-fire in spark ignition engines. SAE Technical Paper 2016-01-0672 (2016). DOI: 10.4271/2016-01-0672 
17. Gosala, D.B., Allen, C.M., Shaver, G.M., Farrell, L., et al.: Dynamic cylinder activation in diesel engines. Int. J. Engine Res. 20(8-9), 849-861 (2019). https://doi.org/10.1177/1468087418 779937

18. Zammit, J.-P., McGhee, M.J., Shayler, P.J., Pegg, I.: The influence of cylinder deactivation on the emissions and fuel economy of a four-cylinder direct-injection diesel engine. Proc. Inst. Mech. Eng. Part D J. Autom. Eng. 228(2), 206-217 (2014). https://doi. org/10.1177/0954407013506182

19. Mo, H., Huang, Y., Mao, X., Zhuo, B.: The effect of cylinder deactivation on the performance of a diesel engine. Proc. Inst. Mech. Eng. Part D J. Autom. Eng. 228(2), 199-205 (2014). https ://doi.org/10.1177/0954407013503627

20. Pillai, S., LoRusso, J., Van Benschoten, M.: Analytical and Experimental evaluation of cylinder deactivation on a diesel engine. SAE Technical Paper 2015-01-2809 (2015). DOI: 10.4271/2015-01-2809

21. Vos, K.R., Shaver, G.M., Joshi, M.C., Ramesh, A.K., et al.: Strategies for using valvetrain flexibility instead of exhaust manifold pressure modulation for diesel engine gas exchange and thermal management control. Int. J. Engine Res. (2019). https://doi. org/10.1177/1468087419880634

22. Schurr, A., Günthner, M., Flierl, R., Woike, D. et al.: Investigation of a cylinder activation concept for a turbocharged direct-injection gasoline engine. SAE Technical Paper 2018-01-1713 (2018). DOI: 10.4271/2018-01-1713

23. Thees, M., Buitkamp, T., Günthner, M., Pickel, P.: High efficiency diesel engine concept with variable valve train and cylinder deactivation for integration into a tractor. In: Proceedings of the ASME 2019 Internal Combustion Engine Division Fall Technical Conference, Chicago (2019). DOI: 10.1115/ICEF2019-7177

24. Technologies, G.: GT-SUITE engine performance application manual: version 2016. Gamma Technologies, Westmont (2016)

25. Pischinger, R., Klell, M., Sams, T.: Thermodynamik der Verbrennungskraftmaschine (in German). Springer (2009). DOI: 10.1007/978-3-211-99277-7

26. Witt, A.: Analyse der thermodynamischen Verluste eines Ottomotors unter den Randbedingungen variabler Steuerzeiten" (in German). Ph.D. Thesis, TU Graz (1999)

27. Hohenberg, G.: Experimentelle Erfassung der Wandwärme von Kolbenmotoren (in German). Habilitation Thesis, TU Graz (1980)

28. Monschein, W., Grabner, P., Eichlseder, H., Quasthoff, M. et al.: Untersuchungen zur Zylinderabschaltung an einem Dieselmotor für den Einsatz in mobilen Arbeitsmaschinen (in German). In: Bargende M., Reuss H., Wiedemann J. (eds), 15th International Stuttgart Symposium. Proceedings, pp. 353-368. Springer Vieweg, Wiesbaden (2015). DOI: 10.1007/978-3-658-08844-6_24

29. Neugärtner, J.: Innere Lastpunktverschiebung bei Dieselmotoren (in German). Ph.D. Thesis, TU Kaiserslautern (2018)

Publisher's Note Springer Nature remains neutral with regard to jurisdictional claims in published maps and institutional affiliations. 